\title{
The Potential Utility of Aqueous Extract of Stevia Rebaudiana Bertoni in Adjunct with Metformin in Treating Diabetes Mellitus
}

\author{
Abdel-Azim Assi ${ }^{1 *}$, Mahran S Abdel-Rahman ${ }^{1}$, Esraa E Ashry ${ }^{1}$, Doaa H Abd-Elhamid ${ }^{1}$, Soad ${ }^{2}$ and \\ Asmaa $^{3}$ \\ ${ }^{1}$ Department of Pharmacology, Faculty of Medicine, Egypt \\ ${ }^{2}$ Department of pharmacy, Cairo, Egypt \\ ${ }^{3}$ Department of Pathology, Faculty of Medicine, Cairo, Egypt
}

*Corresponding author: Abdel-Azim Assi, Department of Pharmacology, Faculty of Medicine, Cairo, Egypt

\section{ARTICLE INFO}

Received: 幽 April 24, 2019

Published: 幽 May 09, 2019

Citation: Abdel-Azim Assi, Mahran S Abdel-Rahman, Esraa E Ashry, Doaa H Abd-Elhamid, Soad, Asmaa. The Potential Utility of Aqueous Extract of Stevia Rebaudiana Bertoni in Adjunct with Metformin in Treating Diabetes Mellitus. Biomed J Sci \& Tech Res 17(5)-2019. BJSTR. MS.ID.003073.

Keywords: Type 2 Diabetes Mellitus; Stevia; Metformin

\author{
ABSTRACT
}

Background: Extract of leaves from the Stevia rebaudiana Bertoni have been used in the traditional treatment of diabetes in Paraguay and Brazil. Stevia is a natural, non-caloric sweetener that is rich in pharmacologically important glycosides. These glycosides have many potential benefits in the mangment of the complications of diabetes. The treatment of type 2 diabetes mellitus (T2DM) is currently unsatisfactory. Therefore, we investigated the possible effects of stevia on treatment of T2DM when concurrently given with common antidiabetic agents in a trial to provide a safe and effective therapeutic antidiabetic combination.

Methods: Type 2 diabetes mellitus was induced in albino rats by IP administration of $230 \mathrm{mg} / \mathrm{kg}$ of nicotinamide (NA) followed by $65 \mathrm{mg} / \mathrm{kg}$ of streptozotocin (STZ). Albino rats were divided into five groups including normoglycemic, diabetic and three diabetic groups in which, the first was treated with aqueous extract of stevia $(300 \mathrm{mg} / \mathrm{kg})$, the second was treated with metformin $(250 \mathrm{mg} / \mathrm{kg})$, and the third was treated with a combination of metformin and stevia extract with the same doses for the period of 21 days. The rats were dissected; blood samples, liver and kidney were further used for detecting biochemical and histopathological changes. BG, insulin, adiponectin, TG, cholestrol, HDL, ALT, AST, urea, creatinine, total protein and TNF $\alpha$ levels were measured in sera. MDA concentration was detected in the liver and kidney.

Results: The aqueous extract of stevia significantly reduced the BG, triglycerides, cholesterol, ALT, AST, urea and creatinine levels in treated rats compared with diabetic rats $(\mathrm{p}<0.05)$. In addition to this, stevia surprisingly, increased insulin and adiponectin levels and decrease TNF $\alpha$ Level in treated rats $(\mathrm{p}<0.05)$. stevia extract also reduced the MDA concentration in the hepatic and renal tissue. Furthermore, stevia compensated for the histopathological damage in diabetic rats. All of these changes were more significant when the stevia extract was combined with metformin.

Conclusion: It is concluded that the stevia alone and/or in combination with other antidiabetic agents can be a new putitive drug used for the treatment of type 2 diabetes mellitus. Moreover, the combination of stevia and metformin has synergistic positive effects on type 2 diabetes mellitus.

\section{Introduction}

Type 2 diabetes mellitus (T2DM) and metabolic syndrome have become major public health concern. There is a sharp increase in the incidence of T2DM and obesity as a result of aging, dietary habits and decreased physical activities [1]. The majority of diabetic 
patients consume sweeteners with low calories to decrease their calorie intake. Most artificial sweeteners, such as cyclamates and saccharine, are a source of high calorie sugars and are potential carcinogens [2]. The increased incidence of diabetes and obesity and the growing concern over the safety of some chemical sweeteners such as aspartame, cyclamate, saccharin, sucralose, etc., have stimulated the use of natural non-calorie sweeteners [3]. In addition, the treatment of T2DM is currently unsatisfactory and new agents are needed [4]. Long-term use of oral hypoglycemic agents induces desensitization to metabolic stimuli in patients with T2DM. In the clinical setting, diabetic subjects often develop secondary failure after long-term treatment with sulfonylureas, which also have numerous side effects. Currently, there is an enormous increase in the use of herbal and other alternative medicines for the treatment of diabetes all over the world.

As a traditional medicine, the plant Stevia rebaudiana Bertoni is used in the treatment of D.M among the Guarani Indians in Paraguay and Brazil [5]. Stevia and its related glycosides have been widely used all over the world as natural zero calorie/lowcalorie sweeteners. Stevia rebaudiana Bertoni is a perennial herb native to certain regions of South America (Paraguay and Brazil) [6]. In 1905, Moises S. Bertoni, an Italian scientist described stevia plant and named it "Stevia rebaudiana Bertoni" after the chemist who first refined it, Dr. Rebaudi. The Native South Americans have been using stevia extract as a sweetener and traditional medicine for several hundred years. Stevia plant proved to posses numerous therapeutic properties for hundreds of years such as antihypertensive, antiobesity and antihyperglycemic effects $[7,8]$. Due to the sweetness and potential therapeutic properties of its leaf; S. rebaudiana Bertoni has attracted economic and scientific interests. It is noteworthy that a multifactorial approach combining the control of blood pressure, blood glucose, and lipid lowering action is most effective in preventing diabetic complications and /or metabolic syndrome. Consequently, therapeutic agents with diversified actions, e.g, antihyperglycemic and blood pressurelowering effects are in great demand.

Metformin is an ancient herbal remedy derived from the plant Galega officinalis (French lilac), a plant traditionally employed in Europe as a drug for diabetes (DM) treatment. In 1950, Stern et al. discovered the clinical usefulness of metformin, and it was introduced into treatment of T2DM in 1957. Since then, the same preparation of metformin has remained in clinical use for over five decades [9]. Now, metformin is recommended as a first-line drug in recent treatment guidelines of the American Diabetes Association (ADA) and European Association for the Study of Diabetes (EASD) [10]. Nevertheless, the need still exists for more thorough investigation of the pharmacological activity of stevia and, particularly; its possible use and interaction with the other known marketed antidiabetic agents. Thus, the present study will be undertaken to study the antidiabetic effect of $S$. rebaudiana alone and in combination with other antidiabetic drugs in rats to prove a new strategy for treatment of patients with diabetes mellitus or to use it in combination with small doses of oral antidiabetic drugs in patient with overt diabetes mellitus.

\section{Materials and Methods}

\section{Drugs and Chemicals}

Streptozotocin and metformin hydrochloride (Glucophage ${ }^{\circledR}$ ) powder were provided by Sigma-Aldrich Chemical Company (Germany) and pharmaceutical companies (cid company, Egypt, Assuit), respectively. Stevia leaves were purchased from.

\section{Plant Material}

Stevia (Stevia rebaudiana Bertoni) leaves were collected from Ayub Agricultural Research Institute (AARI), Faisalabad (Reference no. 606/8). Stevia leaves were washed to remove the dirt, dust and foreign material adhered to the surface. After washing, leaves of stevia were air-dried under shade at room temperature and finely powdered with the help of grinder (MJ-176-NR-3899).

\section{Stevia Aqueous Extract Preparation}

Stevioside was extracted from the dried ground leaves of stevia plant by using water extraction. The dried ground leaves of stevia were mixed with hot water $\left(65^{\circ} \mathrm{C}\right)$ at the ratio of $1: 45(\mathrm{w} / \mathrm{v})$ [15]. The mixture was shaken properly and kept at room temperature for $24 \mathrm{~h}$. It was stirred 2-3 times a day. After $24 \mathrm{~h}$, mixture was filtered through what man filter paper and the filtrate was evaporated using rotary vacuum evaporator (EYELA N-1110S $115 \mathrm{~V}$ ) at $40-45^{\circ} \mathrm{C}$.

\section{The Evaluation of Stevioside in Stevia Leaves}

Stevioside concentration was measured by Macaulay et al's method 21. Filtered solution of stevia extract was injected to HPLC Agilent system. Stevioside (2000 mg/l with 95\% purity) was used as the standard solution. According to the Area Under the Standard Peak (AUSP), stevioside concentration in the stevia plant leaves was determined Figure 1.

\section{Experimental Animals}

Fifty adults male Wistar rats weighing 150-200 g obtained from animal house of Faculty of Medicine, Assiut University were used in all experiments were housed in standard polypropylene cages (four rats per cage). Rats were allowed water and food (laboratory chow) ad libitum. The rats were kept under standard conditions of temperature $\left(22 \pm 2^{\circ} \mathrm{C}\right)$ and relative humidity $(55 \pm 5 \%)$ with 12-light/12-dark cycle. Experimental design and animal handling were according to the guidelines of the Ethical Committee of the Faculty of Medicine, Assuit University, for Animal Use.

\section{Induction of Diabetes}

The diabetes was induced in the rats by a single intraperitonial injection of $230 \mathrm{mg} / \mathrm{kg}$ of nicotinamide (NA) followed by $65 \mathrm{mg} /$ $\mathrm{kg}$ of streptozotocin (STZ), which was freshly prepared in citrate buffer (0.1 M, pH 4.5), after an overnight fasting (Rabbani 2009). 
STZ-injected animals were given $20 \%$ glucose solution for $24 \mathrm{~h}$ to prevent initial drug-induced hypoglycemic mortality. The normal control rats received only distilled water and standard diet Development of diabetes mellitus in the rats was confirmed by testing fasting blood glucose (FBG), after $72 \mathrm{~h}$ of STZ injection. The rats with FBG higher than $200 \mathrm{mg} / \mathrm{dL}$ were considered diabetic and were selected for the study.

\section{Animal Groups and Experimental Design}

Fourty male albino rats were divided into five groups of eight animals in each group each. The animal groups divided as the following:

(i) Group A: saline (Control-non diabetic)

(ii) Group B: saline (control diabetic)

(iii) Group C: diabetic rats received $250 \mathrm{mg} / \mathrm{kg}$ metformin

(iv) Group D: diabetic rats received $300 \mathrm{mg} / \mathrm{kg}$ aquatic extract of stevia

(v) Group E: diabetic rats received $300 \mathrm{mg} / \mathrm{kg}$ aquatic extract of stevia plus $250 \mathrm{mg} / \mathrm{kg}$ of metformin. The aqueous extract of stevia and metformin was dissolved in distilled water and was given orally by stomach tube in a single dose every morning for 21 days. Doses of stevia and metformin were selected depending on our preliminary evaluation and in accordance with previous studies respectively $[11,12]$. The blood glucose levels were measured by Accu- check glucometer on day $0,5,10,15$ and 21 . The blood samples were collected during the period of treatment from tail vein puncture and blood glucose levels were analyzed.

\section{Biochemical Measurements}

Blood samples were collected for biochemical measurements from the orbital sinus of the overnight fasted rats before the experiment. At the end of experimental duration the overnight fasted rats were sacrificed by decapitation. Blood, kidney and liver tissues were obtained from each animal for biochemical measurements. After centrifugation of blood samples for $10 \mathrm{~min}$, the serum was collected for estimation of the levels of glucose, insulin, adiponectin, TNF $\alpha$, TG, cholesterol, HDL, ALT, AST, urea and creatinine. Centrifugation of kidney and liver tissues was done for estimation of MDA levels. The samples after centrifugation could be used directly or stored at $-20^{\circ} \mathrm{C}$ until assay. Serum glucose was determined by Accu-chek Glucometer. TG, cholesterol, HDL, ALT, AST, urea and creatinine levels were determined colorimetrically by spectophotomer. Radioimmunoassay technique was adopted to determine insulin content using an Elisa kit obtained from Calbiotech., USA, by utilizing a rat insulin antiserum to determine the level of rat insulin in serum.

TNF $\alpha$ was determined by using an enzyme-linked immunosorbent assay (ELISA) kit obtained from (Sino Biotech Co., Ltd, by utilizing a rat $\mathrm{TNF} \alpha$ antiserum to determine the level of rat $\mathrm{TNF} \alpha$ in serum. The adipocytokine, adiponectin level in the rat's serum was also determined by using an enzyme-linked immunosorbent assay (ELISA) kit obtained from Elbascience, USA. The level of MDA in kidney and liver tissues was determined colorimetrically by spectophotomer by using a commercially available kit obtained from Biodiagnostic, Egypt.

Preparation of Kidney and Liver Tissue: The liver and one kidney from each animal were kept in 10\% formalin for histopathological and immunohistochemical studies. The rest of liver and other kidney were rinsed in ice-cold saline, dissected, cleaned from fat and other tissues and blotted carefully. The kidney and liver tissues were cuted into small pieces and suitable weights were homogenized in $10 \% \mathrm{w} / \mathrm{v}$ phosphate buffer ( $\mathrm{pH} 7.4$ ) or saline by using a motor-driven Teflon pestle. The homogenate from liver and kidney tissue were centrifuged for $10 \mathrm{~min}$ at 10,000 rpm and the supernatant were used for estimation of malondialdehyde (MDA) directly or stored at $-20^{\circ} \mathrm{C}$ until assay.

Histopathological Examination: Liver and Kidney tissues were obtained from each animal after scarification at the end of experiment. Representative sections were obtained from the liver and kidney tissues. These sections were fixed in $10 \%$ buffered formalin, processed for embedding in paraffin wax by routine protocols and $5-\mu \mathrm{m}$ thickness sections were then cut by microtome. The sections were stained with hematoxylin\& eosin stain (H\&E. stain). Liver sections were examined for hydropic degeneration, vascular congestion, sinusoidal dilatation, lobular inflammation, portal inflammation and necrosis. The kidney tissues were examined for renal glomerular injury, tubular degeneration and vascular congestion. The lesions scoring in both liver and kidney tissues were scored on a semi quantitative scale as follows:

a) $0=$ normal (no change),

b) $1=$ mild $(1 \%-30 \%)$,

c) $2=$ moderate $(31 \%-70 \%)$

d) $3=$ severe $(>70 \%)$, based on the percentages of tissues affected.

Immunohistochemical Analysis: Other sections of 3 to 5 $\mu \mathrm{m}$ thickness were cut from the previous paraffin blocks and mounted on aminopropyl triethxysilane (APSE) coated slides. Once mounted, the slides were dried to remove any water that may be trapped under the section. This was carried by leaving the slides at $60 \mathrm{oC}$ oven overnight. Endothelial nitric oxide synthase (eNOS) was examined immmunohistochemically by using the standardized commercially available Rabbit Polyclonal Antibody (Elabscience Biotechnology Inc, USA) according to manufacturer's instructions. Negative control slides were done by omitting the primary antibody. A section from vascular endothelium was stained as a positive control for eNOS.

Statistical Analysis: Results were expressed as means \pm S.E.M. of the mean $(X \pm S E M)$. Statistical analysis of the differences between groups was done using the one-way analysis of variance 
(ANOVA), followed by Bonferroni test as post hoc analysis. The level of statistical significance was taken at $\mathrm{P}<0.05, \mathrm{P}<0.01$ and $\mathrm{P}<0.001$. All statistics were carried out using GraphPad Prism software (GraphPad; San Diego CA, USA).

\section{Results}

\section{Effect on Blood Glucose Levels (BGL)}

The mean values of blood glucose levels in stevia treated rats were $(451.7 \pm 4.4)$ on day0, $(391.7 \pm 4.4)$ on day 5 , $(350.0 \pm 17.3)$ on day 10 and $(276.7 \pm 8.8)$ on day 15 , until the results became $(205 \pm 14.4)$ on the day 21 . The results showed that, there was a decrease in the mean blood glucose levels upon daily administration Table 1: Effects of oral daily administration of Stevia extract, metf rats during the period of treatment.

\begin{tabular}{|c|c|c|c|c|c|c|c|c|}
\hline \multicolumn{4}{|c|}{ Regimens } & \multicolumn{4}{c|}{ Blood Glucose Levels (Mg/DI) At Time Intervals } \\
\hline Groups & Treatment & Dose (mg/kg) & Number & Day0 & Day5 & Day10 & Day15 & Day21 \\
\hline 1 & Normal control & - & 8 & $130.8 \pm 5.4$ & $126.7 \pm 6.3$ & $121.7 \pm 5$ & $126.7 \pm 4.4$ & $116.7 \pm 5.7$ \\
\hline 2 & Diabetic control & - & 8 & $456.7 \pm 23.3$ & $440 \pm 23.1$ & $406.7 \pm 22$ & $393.3 \pm 20.3$ & $386.7 \pm 18.5$ \\
\hline 3 & Stevia extract & 300 & 8 & $451.7 \pm 4.4$ & $391.7 \pm 4.4$ & $350.0 \pm 17.3$ & $276.7 \pm 8.8$ & $205 \pm 14.4$ \\
\hline 4 & Metformin & 250 & 8 & $477.5 \pm 13$ & $451 \pm 10$ & $435 \pm 17$ & $405 \pm 30$ & $345 \pm 20$ \\
\hline 5 & $\begin{array}{c}\text { Metformin+ Stevia } \\
\text { extract }\end{array}$ & $\begin{array}{c}300 \\
\text { (stevia)+250(metformin) }\end{array}$ & 8 & $468.0 \pm 23$ & $386.6 \pm 21.6$ & $312.0 \pm 17$ & $237.0 \pm 16.5$ & $180 \pm 11.5$ \\
\hline
\end{tabular}

Table 2: Mean of score of liver injuries of the study groups.

\begin{tabular}{|c|c|c|c|}
\hline Type of liver injury & Control non diabetic (Mean \pm SD) & Diabetic Control (Mean \pm SD) & $2.66 \pm 0.51$ \\
\hline $\begin{array}{c}\text { Hydropic } \\
\text { Dedeneration }\end{array}$ & 0 & $1.66 \pm 0.51$ & $1 \pm 0.63$ \\
\hline Sinusoidal dilatation & 0 & $1.50 \pm 0.54$ & $1.33 \pm 0.81$ \\
\hline Vascular congestion & 0 & $1.16 \pm 0.75$ \\
\hline Lobular inflammation & 0 & $0.66 \pm 0.51$ & $0.16 \pm 0.40$ \\
\hline Portal inflammation & 0 & $0.16 \pm 0.40$ & 0.51 \\
\hline Necrosis & 0 & $0.16 \pm 0.40$ & $0.49 \pm 0.66^{* *}$ \\
\hline
\end{tabular}

\section{Effect on Serum Insulin Level}

The insulin levels of diabetic and normal rats are shown in Figure 1. According to the results the insulin level of diabetic control rats $(5.5 \pm 1)$ decreased as compared to normal control rats (14.7 \pm 1.6$)$. While administration of stevia extract $300 \mathrm{mg} / \mathrm{kg} /$ day orally to diabetic rats for three weeks showed significant increase in insulin level $(42.5 \pm 4.9)(p<0.01$, Figure 1) compared to control of stevia extract $(300 \mathrm{mg} / \mathrm{kg})$ for diabetic rats in comparison to control untreated rats as shown in Table 1. The results obtained in this study were in agreement with previous observations of [11]. Its obivious from the results that the stevia extract has a prominent blood glucose lowering effect or in other words antihyperglcemic effects. The results also showed a mild decrease in the BGL in metformin treated rats, While in the combination group of stevia extract $(300 \mathrm{mg} / \mathrm{kg}$ ) and metformin $(250 \mathrm{mg} / \mathrm{kg})$ there is prominent decrease in the mean blood glucose level in comparison to control as shown in Table 2. The decrease on the mean blood glucose level on the combination group was starting from the day $15(237 \pm 16.5)$ and become more prominent on the day 21 to become $(180 \pm 11.5)$. 


\section{Effect on Serum Adiponectin Level}

Daily treatment of diabetic rats with $250 \mathrm{mg} / \mathrm{kgday}$ metformin orally for three weeks produced significant changes in the adiponectin level. Oral administration of metformin to diabetic rats significantly increased the serum adiponectin level as compared to control rats $(\mathrm{p}<0.05$, Figure 2$)$. As shown in the same figure, daily administration of $300 \mathrm{mg} / \mathrm{kg} /$ day stevia extract with $250 \mathrm{mg} / \mathrm{kg} /$ day metformin orally to diabetic rats for the same duration produced significant changes in the serum adiponectin level in comparison to control rats $(\mathrm{p}<0.001$, Figure 2). Stevia extract signficantly increased the effect of metformin on serum adiponectin level in comparison to control rats ( $\mathrm{p}<0.001$, Figure 2$)$. The serum adiponectin was increased from metformin group value of $4.24 \pm 0.13$ to $5.5 \pm 0.2$ by concomitant treatment with stevia extract (Figure 2 ).

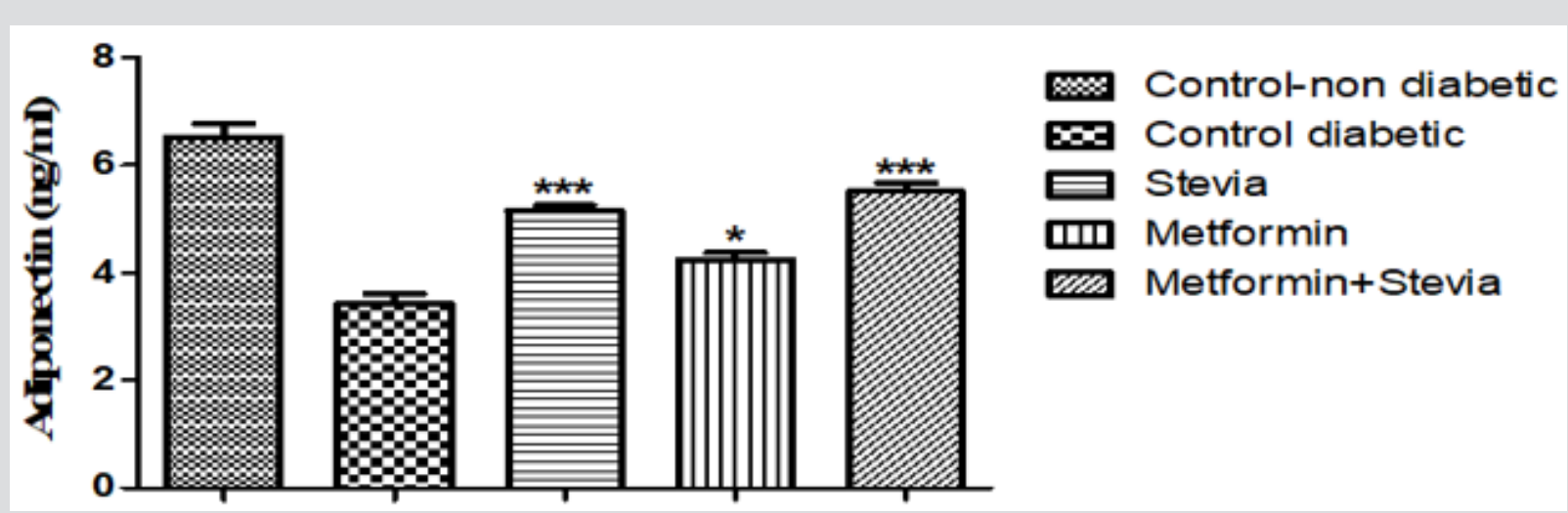

Figure 2: Effect of oral administration of $300 \mathrm{mg} / \mathrm{kg} /$ day stevia extract, $250 \mathrm{mg} / \mathrm{kg}$ metformin and their combination on serum adiponectin level in diabetic rats.

Each value represents the mean \pm S.E.M. of 8 observations.

* Significant difference at $\mathrm{P}<0.05$ vs. control values.

*** Significant difference at $\mathrm{P}<0.001$ vs. control values.

\section{Effect on Serum Lipid Profile Level}

Effect on Serum Cholesterol: The serum cholesterol significantly increased in diabetic rats $(62 \pm 3.2)(\mathrm{P}<0.001$, Figure 3 ) than normal control rats $(43.5 \pm 1.4)$. Administration of $(300 \mathrm{mg} /$ $\mathrm{kg}$ /day) stevia extract significantly decreased the cholesterol level $(53 \pm 1)(\mathrm{P}<0.05$, Figure 3$)$ as compared to control rats. Treatment of diabetic rats with metformin $(250 \mathrm{mg} / \mathrm{kg} /$ day $)$ orally for three weeks significantly decreased the cholesterol level $(52.5 \pm 1)$ $(\mathrm{P}<0.01$, Figure 3) as compared to control rats. Concurrent administration of $(300 \mathrm{mg} / \mathrm{kg} /$ day $)$ stevia extract plus metformin $(250 \mathrm{mg} / \mathrm{kg} /$ day) orally to diabetic rats significantly decreased the cholesterol level $(48 \pm 1.5)(\mathrm{P}<0.001$, Figure 3$)$ as compared to control diabetic rats for the similar duration.

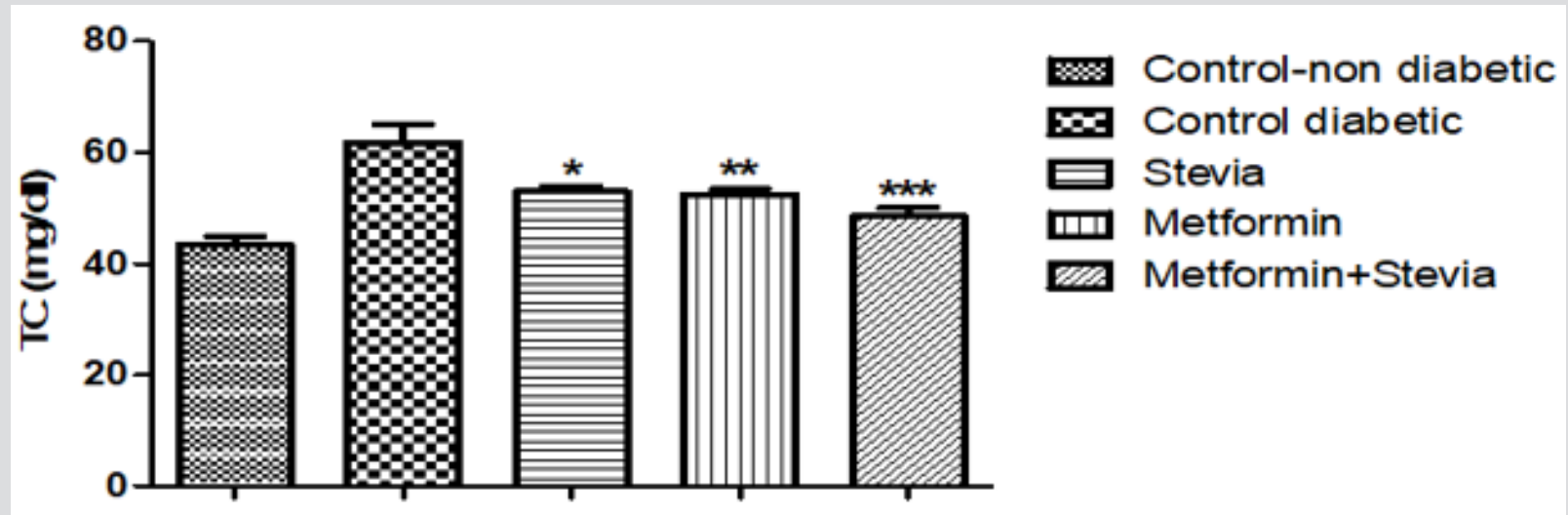

Figure 3: Effect of oral administration of $300 \mathrm{mg} / \mathrm{kg} /$ day stevia extract, $250 \mathrm{mg} / \mathrm{kg}$ metformin and their combination on serum level of cholesterol (TC) in diabetic rats.

Each value represents the mean \pm S.E.M. (one-way ANOVA followed by Bonferroni test).

* Significant difference at $\mathrm{P}<0.05 \mathrm{vs}$. diabetic control values

** Significant difference at $\mathrm{P}<0.01 \mathrm{vs}$. diabetic control values

***Significant difference at $\mathrm{P}<0.001 \mathrm{vs}$. diabetic control values. 
Effect on Serum Triglycerides: As shown in Figure 4, the triglycerides (TG) level significantly increased in diabetic rats $(109 \pm 3.5)(\mathrm{P}<0.001$, Figure 4$)$ as compared to control non diabetic rats. Administration of $(300 \mathrm{mg} / \mathrm{kg} /$ day $)$ stevia extract orally for three weeks significantly decreased the (TG) level $(95.9 \pm 3.6)(\mathrm{P}<$ 0.05 , Figure 4) in diabetic rats. Administration of ( $250 \mathrm{mg} / \mathrm{kg} /$ day $)$ metformin orally for three weeks significantly decreased the (TG) level $(95.7 \pm 2.5)(\mathrm{P}<0.05$, Figure 4$)$ in diabetic rats. concomitant administration of (300 mg/kg/day) stevia extract with metformin (250 $\mathrm{mg} / \mathrm{kg} /$ day) orally in diabetic rats produced a significant decrease in the serum triglyceride as compared to untreated diabetic rats for the similar duration $(90.25 \pm 2.4)(\mathrm{p}<0.001$, Figure 4). The stevia extract increased the effect of metformin on the serum triglycerides.

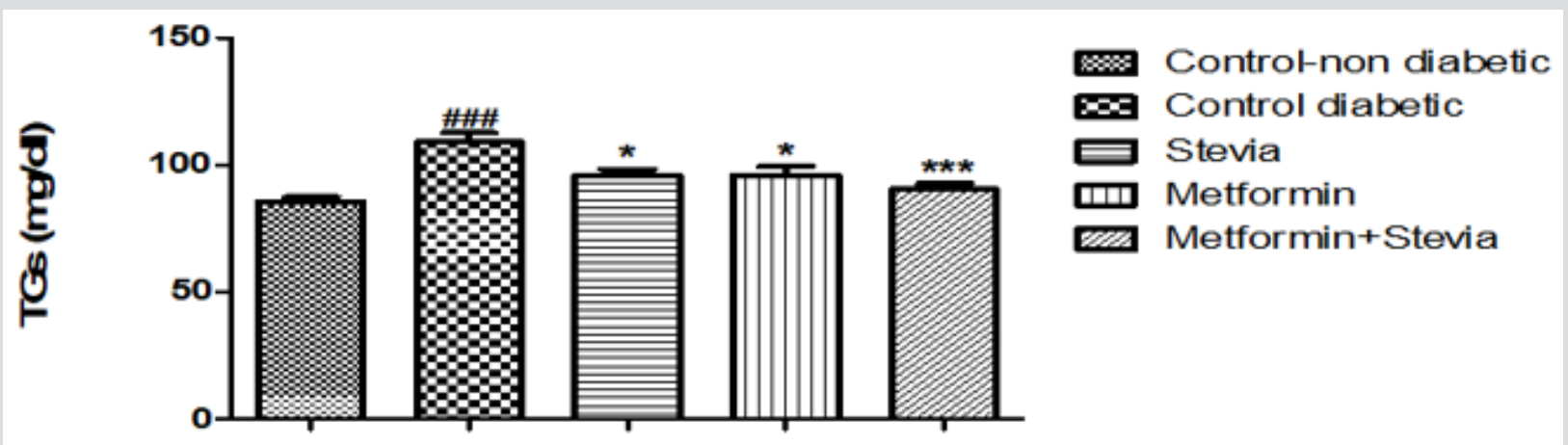

Figure 4: Effect of oral administration of $300 \mathrm{mg} / \mathrm{kg} /$ day stevia extract, $250 \mathrm{mg} / \mathrm{kg}$ metformin and their combination on serum level of triglycerides (TGs) in diabetic rats.

Each value represents the mean \pm S.E.M. (one-way ANOVA followed by Bonferroni test).

*Signficant difference at $\mathrm{P}<0.05$ vs. control values.

***Signficant difference at $\mathrm{P}<0.001$ vs. control values.

\#\#\# Signficant difference at $\mathrm{P}<0.001$ vs. control values.

Effect on Serum High Density Lipoprotein: Daily treatment of diabetic rats with $300 \mathrm{mg} / \mathrm{kg} /$ day stevia extract orally for three weeks produced a significant increase in the serum high density lipoprotein in comparison to untreated diabetic rats $(p<0.001$, Figure 5). Administration of ( $250 \mathrm{mg} / \mathrm{kg} /$ day) metformin orally to diabetic rats produced a significant increase $(28.88 \pm 1.4, \mathrm{p}<0.05$,
Figure 5) in the serum high density lipoprotein in comparison to untreated diabetic rats $(35.25 \pm 1.6)$ for the same period. On the other hand, combined administration of $300 \mathrm{mg} / \mathrm{kg} /$ day stevia extract and $250 \mathrm{mg} / \mathrm{kg} /$ day metformin orally produced a significant increase in the serum high density lipoprotein in comparison to untreated diabetic rats for the same period ( $\mathrm{p}<0.001$, Figure 5).

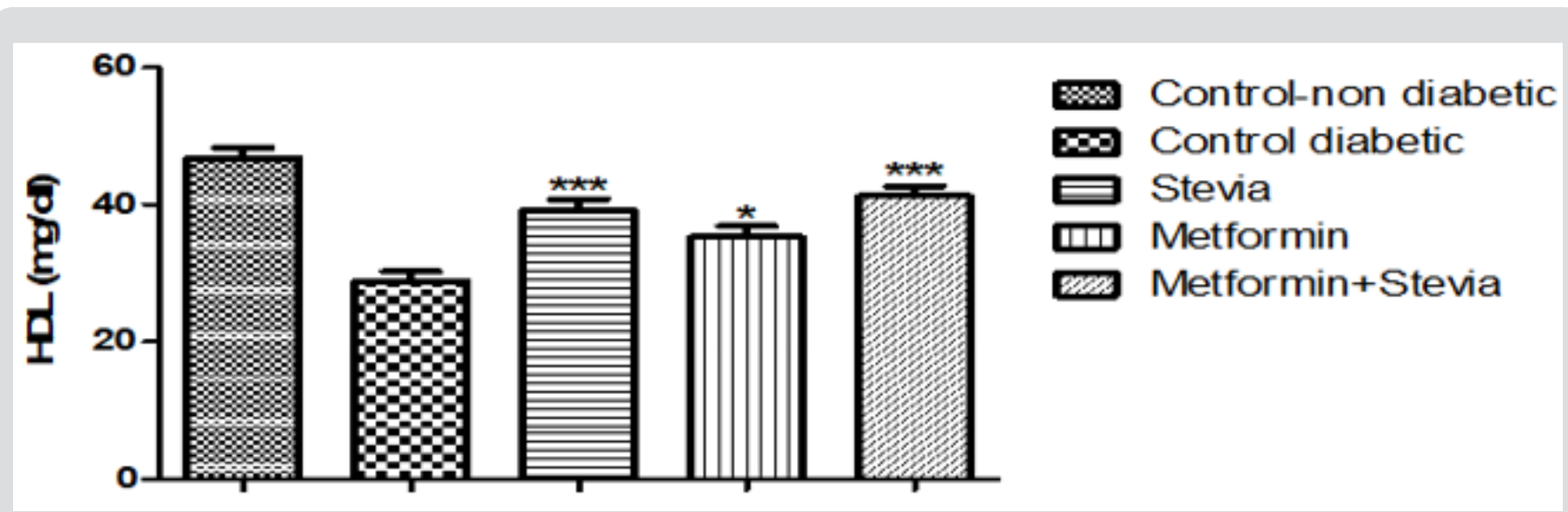

Figure 5: Effect of oral administration of $300 \mathrm{mg} / \mathrm{kg} /$ day stevia extract, $250 \mathrm{mg} / \mathrm{kg}$ metformin and their combination on serum level of high-density lipoprotein (HDL) in diabetic rats.

Each value represents the mean \pm S.E.M. (one-way ANOVA followed by Bonferroni test).

* Significant difference at $\mathrm{P}<0.05$ vs. control values.

***Signficant difference at $\mathrm{P}<0.001$ vs. control values. 


\section{Effect on Liver Function (Enzymes)}

Effect on Serum Aspartate Aminotransferase (AST/GOT) Activity: Administration of (250 mg/kg/day) metformin orally to diabetic rats for three weeks produced insignificant decrease in the serum AST activity as compared to untreated diabetic rats. Combined treatment of diabetic rats with $(250 \mathrm{mg} / \mathrm{kg} /$ day $)$ metformin and (300 mg/kg/day) stevia extract orally to for three weeks significantly decreased the serum AST activity as compared to untreated diabetic rats $(\mathrm{p}<0.01$, Figure 6$)$. The serum AST was decreased from metformin treated group value of $(37 \pm 4.20)$ to (28.10 \pm 3 ) by concomitant treatment with stevia extract (Figure 6).

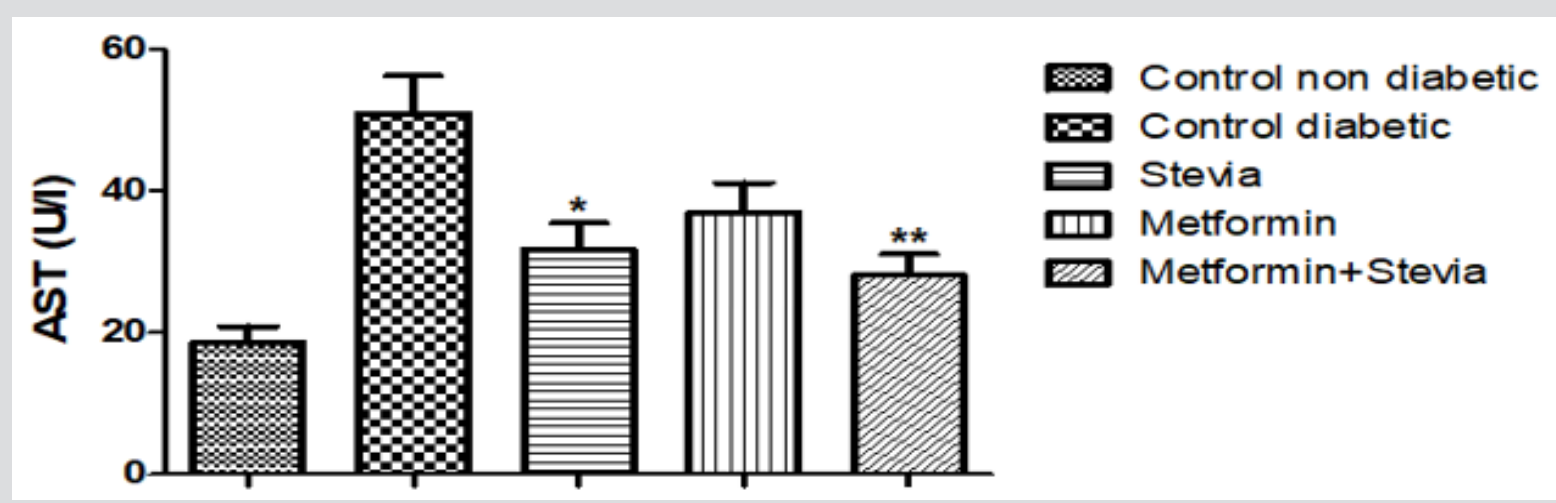

Figure 6: Effect of oral administration of $300 \mathrm{mg} / \mathrm{kg} /$ day stevia extract, $250 \mathrm{mg} / \mathrm{kg}$ metformin and their combination on serum level of aspartate tranferase enzyme (AST) in diabetic rats.

Each value represents the mean \pm S.E.M. (one-way ANOVA followed by Bonferroni test).

*Signficant difference at $\mathrm{P}<0.05$ vs. control values.

**Signficant difference at $\mathrm{P}<0.01$ vs. control values.

Effect on Alanine Aminotransferase (ALT/GPT) Activity: Daily treatment of diabetic rats with $300 \mathrm{mg} / \mathrm{kg} /$ day stevia extract orally for three weeks significantly decreased the activity of serum ALT in comparison to untreated diabetic rats ( $p<0.001$, Figure 7). Similarly, administration of $250 \mathrm{mg} / \mathrm{kg} /$ day metformin orally to diabetic rats for three weeks significantly decreased the activity of serum ALT in comparison to untreated diabetic rats $(p<0.05$, Figure 7). Concomitant administration of ( $250 \mathrm{mg} / \mathrm{kg} /$ day) metformin orally with $300 \mathrm{mg} / \mathrm{kg} /$ day stevia extract orally to diabetic rats for the same duration significantly decreased the serum ALT activity as compared to untreated diabetic rats $(\mathrm{p}<0.001$, Figure 7$)$.

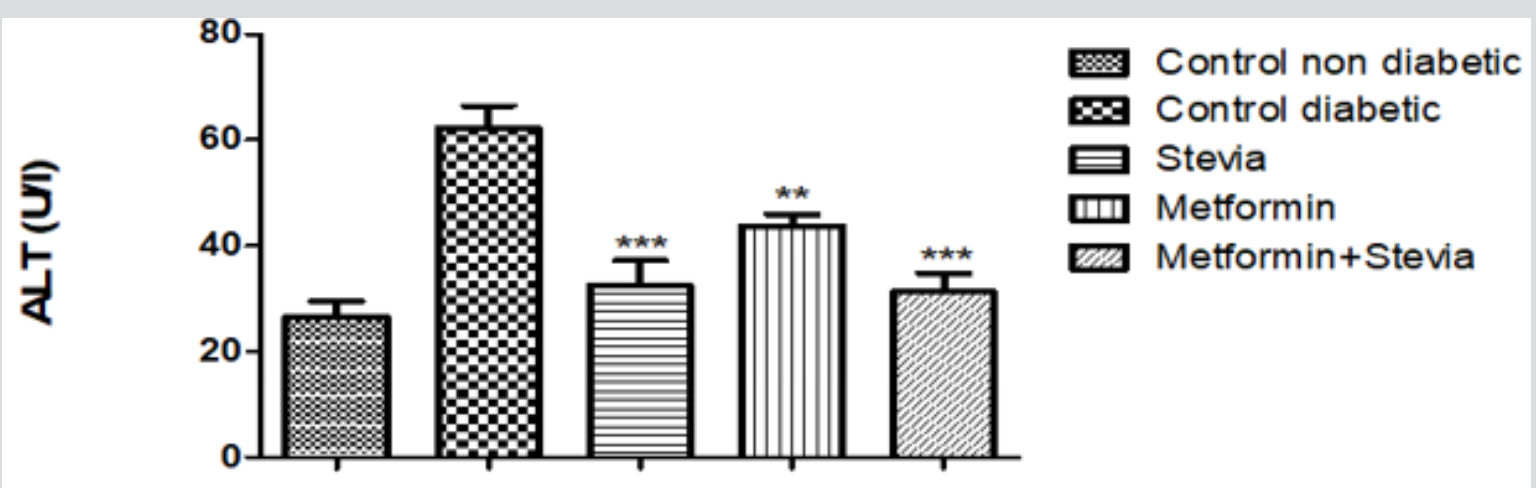

Figure 7: Effect of oral administration of $300 \mathrm{mg} / \mathrm{kg} /$ day stevia extract, $250 \mathrm{mg} / \mathrm{kg}$ metformin and their combination on serum level of alanine tranferase enzyme (ALT) in diabetic rats.

Each value represents the mean \pm S.E.M. (one-way ANOVA followed by Bonferroni test).

**Signficant difference at $\mathrm{P}<0.01$ vs. control values.

\section{Effect on Kidney Function}

Effect on Serum Urea: Daily treatment of diabetic rats with $(250 \mathrm{mg} / \mathrm{kg} /$ day) metformin orally for three weeks produced a significant decrease in the serum urea as compared to untreated diabetic rats $(\mathrm{p}<0.01$, Figure 8$)$. Concomitant administration of $250 \mathrm{mg} / \mathrm{kg} /$ day metformin orally with $300 \mathrm{mg} / \mathrm{kg} /$ day stevia extract orally to rats produced a significant decrease in the serum urea as compared to untreated diabetic rats for the same duration ( $\mathrm{p}<0.001$, Figure 8). 


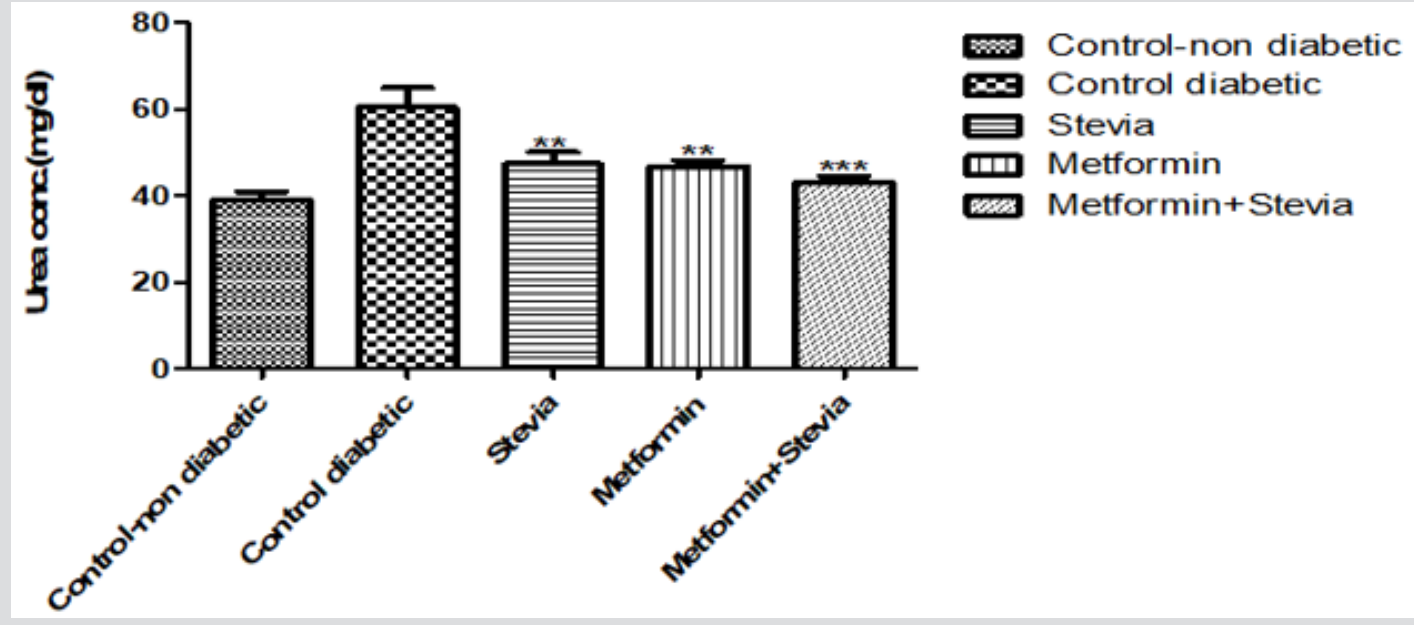

Figure 8: Effect of oral administration of $300 \mathrm{mg} / \mathrm{kg} /$ day stevia extract, $250 \mathrm{mg} / \mathrm{kg}$ metformin and their combination on serum level of urea in diabetic rats.

Each value represents the mean \pm S.E.M. (one-way ANOVA followed by Bonferroni test).

**Signficant difference at $\mathrm{P}<0.01$ vs. control values

***Signficant difference at $\mathrm{P}<0.001$ vs. control values

Effect on Serum Creatinine: Similarly, administration of $250 \mathrm{mg} / \mathrm{kg} /$ day metformin orally to diabetic rats for three weeks produced a significant decrease in the serum creatinine in comparison to untreated diabetic rats for the same period $(\mathrm{p}<0.05$,
Figure 9). Co-administration of $250 \mathrm{mg} / \mathrm{kg} /$ day metformin orally with $300 \mathrm{mg} / \mathrm{kg} /$ day stevia extract orally to diabetic rats for three weeks produced a significant decrease in the serum creatinine as compared to untreated diabetic rats $(\mathrm{p}<0.001$, Figure 9).

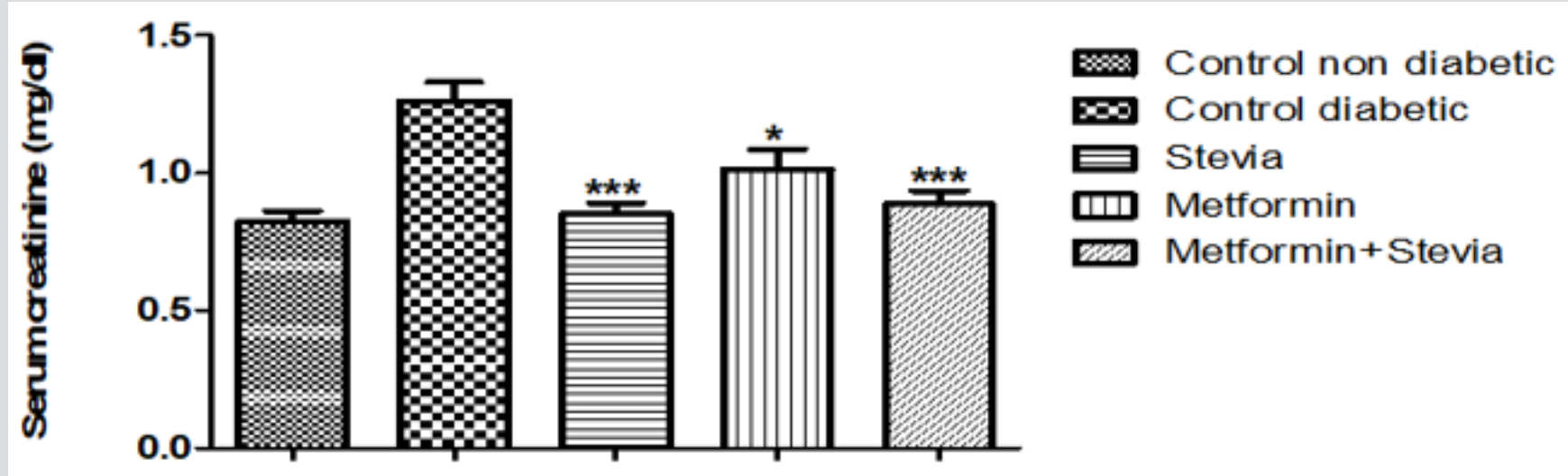

Figure 9: Effect of oral administration of $300 \mathrm{mg} / \mathrm{kg} /$ day stevia extract, $250 \mathrm{mg} / \mathrm{kg}$ metformin and their combination on serum level of creatinine in diabetic rats.

Each value represents the mean \pm S.E.M. (one-way ANOVA followed by Bonferroni test).

*Signficant difference at $\mathrm{P}<0.05$ vs. control values.

**Signficant difference at $\mathrm{P}<0.01$ vs. control values.

***Signficant difference at $\mathrm{P}<0.001$ vs. control values.

\section{Effect on Serum Total Protein Concentration: Administration} of $250 \mathrm{mg} / \mathrm{kg} /$ day metformin orally to diabetic rats for three weeks produced insignificant decrease in the total protein conc. in comparison to untreated diabetic rats for the same period $(p>0.05$, Figure10). Combined administration of $250 \mathrm{mg} / \mathrm{kg} /$ day metformin orally with $300 \mathrm{mg} / \mathrm{kg} /$ day stevia extract orally to rats for three weeks produced a significant decrease in the total protein conc. as compared to untreated diabetic rats $(\mathrm{p}<0.01$, Figure 10$)$.
Effect on Serum Level of Tumour Necrosis Factor- $\alpha$ (TNF- $\alpha$ ): Treatment of diabetic rats with $250 \mathrm{mg} / \mathrm{kg} /$ day metformin orally for three weeks produced a significant decrease in the serum tumor necrosis factor in comparison to untreated diabetic rats for the same period ( $p<0.05$, Figure11). Co-administration of $250 \mathrm{mg} / \mathrm{kg} /$ day metformin with $300 \mathrm{mg} / \mathrm{kg}$ /day stevia extract orally to rats for three weeks produced a significant decrease in the serum tumor necrosis factor as compared to untreated diabetic $(\mathrm{p}<0.001$, Figure 11). 


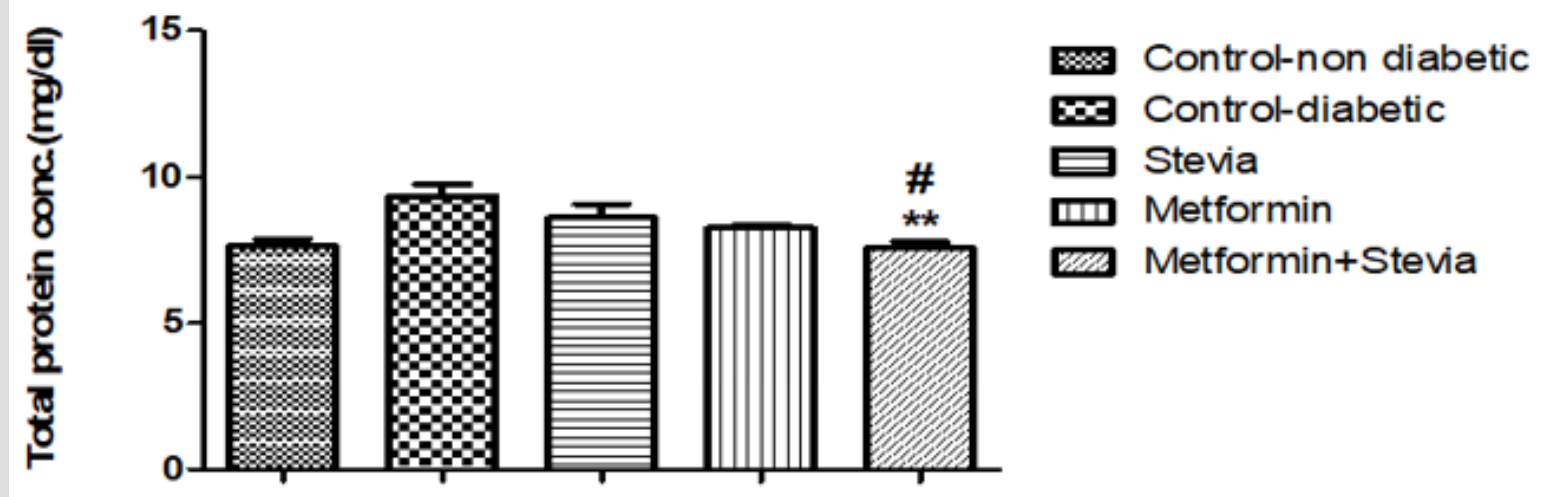

Figure 10: Effect of Effect of chronic treatment with stevia extract, metformin and their combination on the serum total protein conc. in diabetic rats.

Each value represents the mean \pm S.E.M. of 8 observations. (One-way ANOVA followed by Bonferroni test).

** Significant difference at $\mathrm{P}<0.01$ vs. control values.

\#Significant difference at $\mathrm{P}<0.05$ vs. metformin values.

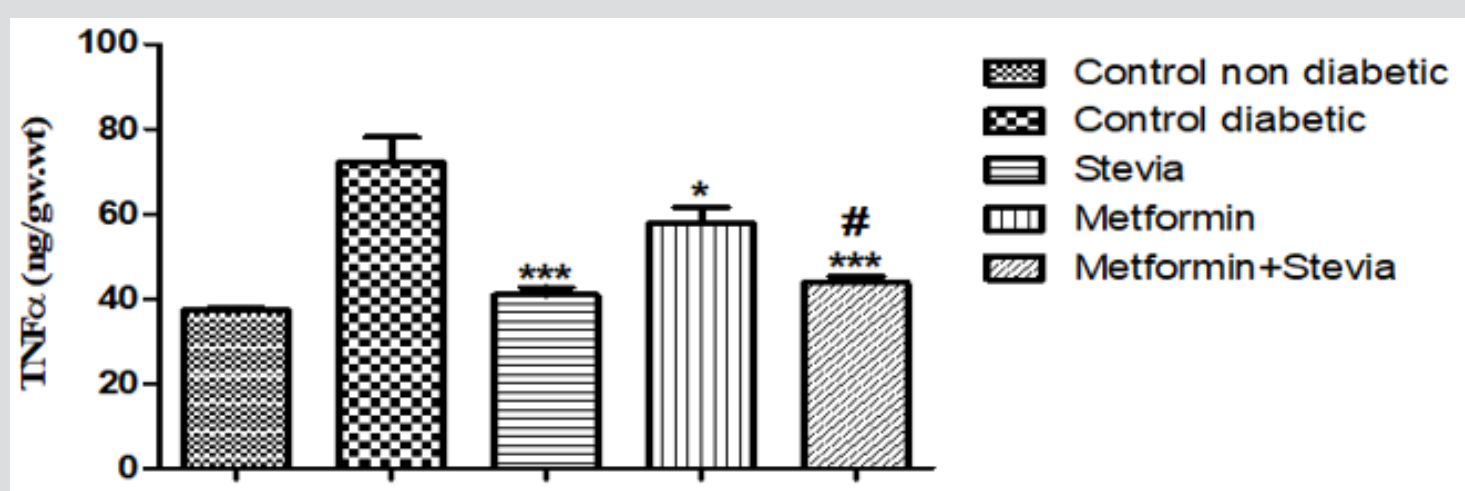

Figure 11: Effect of oral administration of $300 \mathrm{mg} / \mathrm{kg} /$ day stevia extract, $250 \mathrm{mg} / \mathrm{kg}$ metformin and their combination on serum level of tumour necrosis factor- $\alpha$ (TNF-a) in diabetic rats.

Each value represents the mean \pm S.E.M. (one-way ANOVA followed by Bonferroni test).

* Significant difference at $\mathrm{P}<0.05$ vs. control values.

*** Significant difference at $\mathrm{P}<0.001$ vs. control values.

\#Significant difference at $\mathrm{P}<0.05$ vs. metformin values.

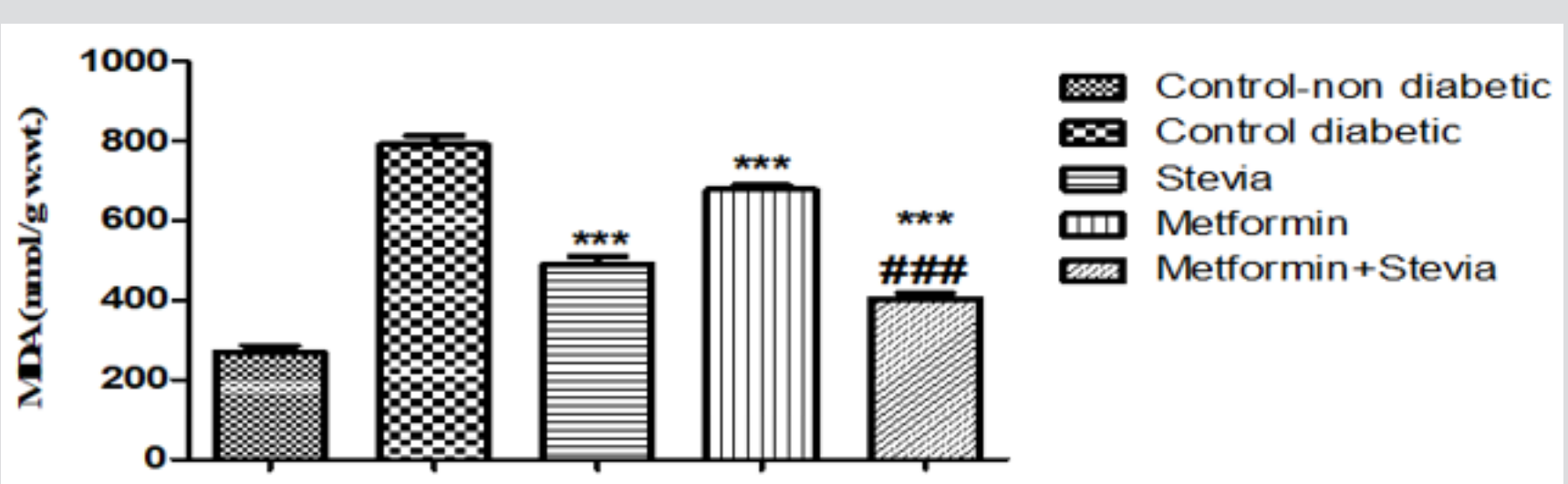

Figure 12: Effect of oral administration of $300 \mathrm{mg} / \mathrm{kg} /$ day stevia extract, $250 \mathrm{mg} / \mathrm{kg}$ metformin and their combination on serum level of tumour necrosis factor- $\alpha$ (TNF- $\alpha$ ) in diabetic rats.

Each value represents the mean \pm S.E.M. (one-way ANOVA followed by Bonferroni test).

*** Significant difference at $\mathrm{P}<0.001$ vs. control values.

\#\#\# Significant difference at $\mathrm{P}<0.05$ vs. metformin values. 
Effect on Renal Level of Malondialdehyde (MDA): Treatment of diabetic rats with $250 \mathrm{mg} / \mathrm{kg}$ /day metformin orally for three weeks produced significant decrease in the renal MDA level in comparison to untreated diabetic rats for the same period $(\mathrm{p}<0.001$, Figure 10). Combined administration of $250 \mathrm{mg} / \mathrm{kg} /$ day metformin orally with $300 \mathrm{mg} / \mathrm{kg} /$ day stevia extract orally to diabetic rats for the same duration produced a significant decrease in the renal MDA level as compared to untreated diabetic rats and metformin treated rats $(\mathrm{p}<0.001$, Figure 12).

Histopathological Examination of The Liver Tissue: Liver sections from the normal control group were histologically unremarkable. On the contrary, sections from diabetic control rats showed significant histopathologic changes in the form of severe hydropic degeneration, sinusoidal dilatation, vascular congestion and focal areas of inflammation and necrosis. Whereas, changes indicate chronic illness as hepatic fibrosis and macrovesicular steatosis were not detected. As regard liver injuries, Improvement of the hepatic injuries was noted in stevia treated group with insignificant difference in comparison to those treated by metformin Table 3. It is of note that combination of Stevia \&Metformin significantly reduced the liver injuries than those treated with Stevia alone Table 4. Also, combination of Stevia \& Metformin significantly reduced the liver injuries than those treated with Metformin alone Table 4.

Table 3: Mean of score of renal injuries of the study groups.

\begin{tabular}{|c|c|c|c|}
\hline $\begin{array}{c}\text { Type of Renal } \\
\text { Injury }\end{array}$ & $\begin{array}{c}\text { Control } \\
\text { Non-Diabetic }\end{array}$ & $\begin{array}{c}\text { Diabetic Con- } \\
\text { trol }\end{array}$ & Metformin \\
\hline $\begin{array}{c}\text { Glomerular } \\
\text { injury }\end{array}$ & 0 & $1 \pm 0.0$ & $0.33 \pm 0.51$ \\
\hline $\begin{array}{c}\text { Tubular degen- } \\
\text { eration }\end{array}$ & 0 & $2.66 \pm 0.51$ & $2.50 \pm 0.54$ \\
\hline $\begin{array}{c}\text { Vascular con- } \\
\text { gestion }\end{array}$ & 0 & $2.33 \pm 0.51$ & $1.16 \pm 0.98$ \\
\hline $\begin{array}{c}\text { Mean score of } \\
\text { renal injuries }\end{array}$ & 0 & $1.99 \pm 0.88^{* *}$ & $1.33 \pm 1$ \\
\hline
\end{tabular}

Table 4: The difference between the mean liver and renal injuries scores in the study groups.

\begin{tabular}{|c|c|c|}
\hline $\begin{array}{c}\text { Type of Renal } \\
\text { Injury }\end{array}$ & $\begin{array}{c}\text { CP Value of The Mean } \\
\text { Liver Injuries Score }\end{array}$ & $\begin{array}{c}\text { P Value of The Mean } \\
\text { Renal Injuries Score }\end{array}$ \\
\hline $\begin{array}{c}\text { Normal control } \\
\text { Diabetic group }\end{array}$ & $0.002^{*}$ & $0.037^{*}$ \\
\hline $\begin{array}{c}\text { Stevia } \\
\text { Metformin }\end{array}$ & 0.685 & 0.369 \\
\hline $\begin{array}{c}\text { Stevia } \\
\text { Metformin }\end{array}$ & $0.013^{*}$ & $0.043^{*}$ \\
\hline $\begin{array}{c}\text { Metformin } \\
\text { Metaformin \& } \\
\text { Stevia }\end{array}$ & $0.005^{*}$ & $0.04^{*}$ \\
\hline
\end{tabular}

The Histopathological Examination of The Kidney Tissue: Sections from the kidney of the normal control group were histologically unremarkable. Alternatively, sections of diabetic control group showed features of early diabetic renal damage in the form of hydropic degeneration of the tubules, vascular congestion and mild enlargement of glomeruli with glomerular capillaries congestion. The mean of the renal injuries was summarized in Table 3. It is of note that, the mean of renal injuries were significantly higher in the diabetic rats when compared to the control group (Table 4). Lower mean of renal injuries was observed in Stevia\& Metformin treated group than those treated with Metformin alone (Table 1). However, this difference was statistically insignificant (Table 4). Combination of Stevia \& Metformin significantly reduced the renal injuries than those treated with Stevia alone (Table 4).

Immunohistochemical Analysis: The immunohistochemical analysis of the kidney tissue obtained from the rats after three weeks of administration of $300 \mathrm{mg} / \mathrm{kg} /$ day stevia extract orally showed a decrease in eNOS protein expression (Fig.) and an increase in the protein expression of iNOS (Fig.) as compared to control animals (Fig.). Co-administration of $300 \mathrm{mg} / \mathrm{kg} /$ day stevia extract with metformin to diabetic rats increased the protein expressions of eNOS (Fig.) and iNOS (Fig.), while daily administration of $250 \mathrm{mg} / \mathrm{kg} /$ day metformin alone to diabetic rats decreased the protein expression of eNOS (Fig.) and iNOS (Fig.).

\section{Discussion}

The currently available hypoglycemic agents for management of diabetes mellitus are ineffective and have certain drawbacks. The United Kingdom Prospective Diabetes Study (UKPDS) showed that monotherapy with oral agents often fails to maintain glycemic control over time, and many patients have to switch to treatment with combinations of oral agents or insulin therapy. Therefore, there is a demand for new natural-based medicinal compounds with diversed actions. Stevia rebaudiana Bertoni is a medicinal plant with multiple potential benefits. Metformin is a widely used oral glucose-lowering drug for type 2 diabetes. The use of biguanide as a first-line drug depends on evidence showing that metformin reduces incidence of cardiovascular events as well as total mortality, in particular in mega-trials of T2DM such as the UK Prospective Diabetes Study (UKPDS) (UKPDS, 1998). In agreement with previous findings, our results demonstrate that treatment of diabetic rats with stevia extract orally at a dose $(300 \mathrm{mg} / \mathrm{kg} /$ day $)$ for three weeks produced favorable effects on blood glucose levels. Similary, concurrent administration of stevia extract $(300 \mathrm{mg} / \mathrm{kg} /$ day) and metformin $(250 \mathrm{mg} / \mathrm{kg} /$ day $)$ orally for the same duration also reduced blood glucose levels.

The results indicated that aqueous extract from leaves of stevia rebaudiana, produced a significant long term reduction in blood glucose levels especially when combined with other hypoglycemic agents, which provide a good control of hyperglycemia in diabetic rats. This finding is collaborated with the previous researches which proved a positive effects of stevia extract on diabetic rats. This study demonstrates that stevia extract have a good efficacy in controlling diabetes not only via decreeing the blood glucose level but also via increasing the insulin level. Previous study showed that 
stevioside was able to regulate blood glucose levels by enhancing not only insulin secretion and sensitivity but also insulin utilization in insulin deficient rats which was due to decreased PEPCK gene expression in rat liver [13] .These results are in agreement with $[14,15]$ who also observed that stevia aqueous extract lowered the random and fasting blood.

We observed that the effects of stevia extract on control of blood glucose are more pronounced when combined with metformin. Previous studies showed that adiponectin plays a central role in obesity, insulin resistance and type 2 diabetes. Studies have shown that adiponectin administration in humans and rodents has insulinsensitizing, anti-atherogenic, and anti-inflammatory effects, and, in certain settings, also decreases body weight $[16,17]$. Concerning to the effect of metformin in obesity and related diseases, metformin has found to decrease the basal metabolic index and improved inflammatory and cardiovascular-related obesity parameters especially insulin sensitivity and the adiponectin level [18]. Our results indicate that aqueous extract of stevia has a significant effect on increasing the serum level of adiponectin. Thus the combination of stevia and metformin could provide potential therapeutic targets in the treatment of obesity, insulin resistance and type 2 diabetes.

Combined administration of stevia extract and metformin Showing improvement in lipid profile, regarding serum triglycerides and cholesterol with significant reduction in their levels. Also the serum high density lipoprotein was significantly increased. Thus, the combination of stevia extract and metformin has a synergistic effect on lipid profile. Therefore, it appears that stevia extract and metformin may provide benefits in conditions associated with impaired glucose tolerance, dyslipidemia and reduced insulin sensitivity. During diabetes or insulin resistance, failure of insulinstimulated glucose uptake by fat and muscle causes high glucose concentration in blood. Since high blood glucose is susceptible to oxidation, hyperglycemia causes high ROS production and, in turn, leads to high Malondialdehyde (MDA) levels in tissues [19]. MDA is the principal and most studied product of polyunsaturated fatty acid peroxidation which plays important role in etiopathology of several chronic diseases including diabetes [20]. Elevated levels of lipid peroxidation products (MDA) were found in diabetic rats. This might be due to overproduction of peroxides and inhibition of activities of peroxidases which is a common event in diabetic rats. Reduction of renal and hepatic MDA level was noted in stevia and stevia \& metformin groups.

Consistent with the results of the current study, many experimental studies indicated that the antioxidant property of stevia extract might be due to the presence of substantial amounts of flavonoids and phenolic contents [21,22]. Currently, there is renewed interest in plant-based medicines and functional foods modulating physiological effects in the prevention and cure of diabetes. On the other hand, oxidative stress along with hyperglycemia plays a major role in the pathogenesis of diabetes. Owing to the antihyperglycemic and anti-oxidative potential of stevia extract, thus the extract of stevia may be new therapeutic agent inprevention and treatment of diabetes. The serum levels of ALT and AST were decreased in diabetic rats after treatment with aqueous extract of stevia. There is a significant decrease in serum of hepatic enzymes in stevia and stevia extract \& metformin groups, which was associated with a marked improvement in the liver function and structure.

Stevia extract and its polyphenol caused a significant decrease in the levels of ALT and AST serums. These results are in accordance with $[24,25]$ who demonstrated the hepatoprotective effect of stevia extract on the liver damage of diabetic rats. It was likely that the reduced levels of ALT and AST serums by the stevia extract and its antioxidant effect are an indication of alleviation of plasma membrane damage produced by diabetes. Also, STZ kidney injury is characterized by both diagnostic indicators and histopathological analysis [27]. The levels of renal markers such as urea and creatinine were increased in the STZ treated rats $[28,29]$. Animal studies also reported that STZ induced nephrotoxicity which characterized by proximal tubular nephropathy, glomerular sclerosis, interstitial fibrosis, renal tubular epithelial cell necrosis, leukocyte infiltration, and apoptosis of various renal cells [30]. In agreement with these findings, our results demonstrate that STZ produced a marked elevation of the renal markers, which was associated with impairment in the kidney structure were observed in control diabetic group.

The serum urea and creatinine levels were significantly decreased in stevia and stevia extract \& metformin groups. The histopathological examination of kidney tissue revealed Lower mean of renal injuries was observed in treated groups in comparison with control group. This is in accordance with similar resuts observed by previous researchers that stevia leaves extract have a significant role in alleviating kidney damage in the STZ-diabetic rats besides its hypoglycemic effect [31]. Our results support the validity of stevia leaves extract for the management of diabetes as well as diabetes-induced renal disorders. It is known that hyperglycemia is commonly associated with disturbance of lipid metabolism, leading to the increased total cholesterol and low-density lipoprotein as well as decreased high density lipoprotein levels [6,29-32]. The long-term prognosis of type 2 diabetes relies on the treatment of hyperglycemia, and on coexisting conditions, such as hypertension, dyslipidemia and obesity, as delineated in the United Kingdom Prospective Diabetes Study (UKPDS) [33]. As approximately 50\% of type 2 diabetic subjects suffer from hypertension and dyslipidemia which cause a 2-3fold increased the risk of CAD [34]. Consequently, the pharmacologic intervention in type 2 diabetes should aim to lower blood glucose and also lipid concentration. Our results revealed that treatment with stevia extract significantly decreased TC and TG levels and increased HDL level in treated diabetic rats. It has been reported that most drugs which were used in the treatment of hypercholesterolemia decrease both total and HDLcholesterol levels $[35,36]$. 
However, SR aqueous extract reduced total cholesterol level and increased HDL-cholesterol level. These results are collaborated with previous results [39-42]. Studies on humans also indicated that the consumption of SR extracts increased the level of HDL and reduced the levels of cholesterol, triglycerides, and low-density lipoproteins significantly [43]. Therefore, aqueous extract from Stevia leaves could be used as natural anti-hyperlipidemic drug for the treatment of hyperlipidemia and its associated complications (Ahmad et al., 2018). Besides antihyperglycemic efficacy, metformin represents increasing evidence of a potential efficacy in improving dyslipidemia [44]. Studies have shown that metformin decreased plasma total cholesterol and TG levels and increased HDL-c level. Similar to prior observations, our current study supported that metformin significantly reduced total cholesterol and TG levels and increased HDL-cholesterol level. Thus, combination of stevia extract and metformin could provide additive benefits on subjects with dyslipidemia and overweight/obese.

It is well known that, the proinflammatory cytokine tumour necrosis factor TNF-alpha has been implicated as a causative factor in obesity-associated insulin resistance and the pathogenesis of type 2 diabetes, exerting its actions through the immune and inflammatory pathways. Wang et al., 2012 Suggested that the proinflammatory cytokine TNF-alpha was significantly downregulated together with the expressions of interleukin 6 (IL6), interleukin 10 (IL1)), and interleukin 10 (IL10), among other chemotactic and pro-inflammatory cytokines. Therefore, stevioside was seen to be able to potentiate in the reduction of insulin resistance through reducing the inflammation in adipose tissues by regulating TNF?. Our results indicate that stevia extract significantly reduced serum level of TNF- $\alpha$. The effect of metformin on TNF? were more pronounced when it combined with stevia extract leading to a significant decrease in its level as compared to diabetic rats treated with metformin alone. These results with increasing the insulin level suggesting that the effect of stevia extract on TNF? may be the cause of increasing insulin level and decreasing the insulin resistance.

\section{Conclusion}

The present study suggests that aqueous extract from stevia leaves may decrease the blood glucose level, while serum insulin and adiponectin levels were significantly increased in diabetic rats as compared with the diabetic control rats after 3 weeks study period. The aqueous extract of stevia also showed significant decrease in lipid profile, TNF $\alpha$ and oxidative stress marker, (MDA). Moreover, the diabetic rats treated with stevia aqueous extract exhibited values for hepatic and renal function near normal levels. These effects of stevia extract were more prominent when it is combined with metformin. It is concluded that combination of aqueous extract of stevia at a concentration $300 \mathrm{mg} / \mathrm{kg}$ plus $250 \mathrm{mg} / \mathrm{kg}$ metformin may provide an effective therapeutic anti-diabetic combination for the treatment of diabetes and its associated complications.

\section{Acknowledgement}

The present article was extracted from the thesis written by Doaa Hamdy Abd El-hamied and financially supported by Science and technology development fund (STDF) Grant No, 12667.

\section{References}

1. Zimmet PJ, McCarty DJ, de Courten MP (1997) The global epidemiology of non-insulin dependent diabetes mellitus and the metabolic syndrome. Diabetes Complications 11(2): 60-68.

2. Weihrauch MR, Diehl V (2004) Artificial sweeteners - do they bear a carcinogenic risk. Ann Oncol 15(10): 1460-1465.

3. Brahmachari Goutam, Lalan C Mandal, Rajiv Roy, Sadhan Mondal, Arun K Brahmachari (2011) Stevioside and Related Compounds - Molecules of Pharmaceutical Promise: A Critical Overview. Arch Pharm Chem Life Sci 344(1): 5-19.

4. Jeppesen PB, Dyrskog SE, Agger A, Gregersen S, Colombo M, et al. (2006) Can stevioside in combination with a soy-based dietary supplement be a new useful treatment of type 2 diabetes? An in vivo study in the diabetic goto-kakizaki rat. Rev Diabet Stud 3(4): 189-199.

5. Soejarto DD, Kinghorn AD, Farnsworth NR (1982) Potential sweetining agent of plant origin III: Organo leptic evaluation of Stevia leaf herbarium samples for sweetness J Nat Prod 45(5): 590-599.

6. Katayama O, Sumida T, Hayashi H, Mitsuhashi H (1976) The practical application of Stevia research and devolvement data. ISU Company pp. 747.

7. Jeppesen PB, Gregersen S, Alstrup KK, Hermansen K (2002) Stevioside induces antihyperglycaemic, insulinotropic and glucagonostatic effects in vivo: studies in the diabetic Goto-Kakizaki (GK) rats. Phytomedicine 9(1): 9-14.

8. Jeppesen PB, Gregersen S, Rolfsen SED, Jepsen M, Colombo M, et al. (2003) Antihyperglycemic and blood pressure-reducing effects of stevioside in the diabetic Goto-Kakizaki rat. Metabolism 52(3): 372-378.

9. Fujita Yoshihito, Nobuya Inagaki (2017) Metformin: New Preparations and Nonglycemic Benefits. Curr Diab Rep 17(1): 5.

10. Inzucchi SE, Bergenstal RM, Buse JB, Michaela Diamant, Ele Ferrannini, et al. (2015) Management of hyperglycemia in type 2 diabetes, 2015: a patient-centered approach: update to a position statement of the American Diabetes Association and the European Association for the Study of Diabetes. Diabetes Care 38(1): 140-149.

11. Misra H, Soni M, Silawat N, Mehta BK, Jain DC (2011) Antidiabetic activity of medium-polar extract from the leaves of Stevia rebaudiana Bert. (Bertoni) an alloxan-induced diabetic rats. J Pharm Bioallied Sci 3(2): 242-248.

12. Matthaei S, Reibold JP, Hamann A, Benecke H, Häring HU, et al. (1993) In vivo metformin treatment ameliorates insulin resistance: evidence for potentiation of insulin-induced translocation and increased functional activity of glucose transporters in obese (fa/fa) Zucker rat adipocytes. Endocrinology 133(1): 304-311.

13. Geuns JMC, Buyse J, Vankeirsbilck A, Temme EHM (2007) Metabolism of stevioside by healthy subjects. Exp Biol Med 232(1): 164-173.

14. Assaei R, Mokarram P, Dastghaib S, Darbandi S, Darbandi M, et al. (2016) Hypoglycemic effect of aquatic extract of Stevia in pancreas of diabetic rats: PPAR $\gamma$-dependent regulation or antioxidant potential. Avicenna J med Biotech 8(2): 65-74

15. Akbarzadeh S, Eskandari F, Tangestani H, Bagherinejad ST, Bargahi A, et al. (2015) The effect of Stevia rebaudiana on serum omentin and visfatin level in stz-induced diabetic rats. J diet Suppl 12(1): 11-12.

16. Ghoshal K, Bhattacharyya M (2015) Adiponectin: Probe of the molecular paradigm associating diabetes and obesity. World J Diabetes 6(1): 151166. 
17. Arunkumar E Achari, Sushil K Jain (2017) Adiponectin, a Therapeutic Target for Obesity, Diabetes, and Endothelial Dysfunction. Int J Mol Sci 18(6): 1321.

18. Aghajanyan Anush, Movsisyan Zaruhi, Trchounian Armen (2017) Antihyperglycemic and Antihyperlipidemic Activity of Hydroponic Stevia rebaudiana Aqueous Extract in Hyperglycemia Induced by Immobilization Stress in Rabbits. BioMed Research International.

19. Anabtawi A, Miles JM (2016) Metformin: nonglycemic effects and potential novel indications. Endocr Pract 22(8): 999-1007.

20. Belén Pastor Villaescusa, M Dolores Cañete, Javier Caballero Villarraso, Raúl Hoyos, Miriam Latorre, et al. (2017) Metformin for Obesity in Prepubertal and Pubertal Children: A Randomized Controlled Trial. Pediatrics 140(1): e20164285

21. Christiansen JS, Gammelgaard J, Frandsen M, Parring HH (1981) Increased kidney size, glomerular filtration rate and renal plasma flow in short term insulin dependent diabetics. Diabetologia 20(4): 451-456.

22. Das S, VasishtS, Snehalta Das N,Shrivastava M (2000) Correlation between total antioxidant status and lipid peroxidation in hypercholesterolemia. Current Science 78(4): 486.

23. Davis BJ, Xie Z, Viollet B, Zou MH (2006) Activation of the AMP-activated kinase by antidiabetes drug metformin stimulates nitric oxide synthesis in vivo by promoting the association of heat shock protein 90 and endothelial nitric oxide synthase. Diabetes 55(2): 496-505.

24. Del Rio D, Stewart AJ, Pellegrini N (2005) A review of recent studies on malondialdehyde as toxic molecule and biological marker of oxidative stress. Nutr Metab Cardiovasc Dis 15(4): 316-328.

25. Díaz A, Villegas O, Lino AC, Treviño S, Carmona Gutie'rrez G, et al. (2013) Hypoglucemic and antihyperlipidemic activity of $\mathrm{TiO}_{2}$ nanostructuredconjugated Stevia rebaudiana Bertoni in a model of diabetes mellitus in rats. Rev Mex Cienc Farm 44(4): 36-42.

26. Garber AJ, Abrahamson MJ, Barzilay JI, Blonde L, Bloomgarden ZT, et al. (2017) Consensus Statement by the American Association of Clinical Endocrinologists and American College of Endocrinology on the Comprehensive Type 2 Diabetes Management Algorithm - 2017 Executive Summary. Endocr Pract 23(2): 207-238.

27. Geerling JJ, Boon MR, van der Zon GC, van den Berg SA, van den Hoek AM, et al. (2014) Metformin lowers plasma triglycerides by promoting VLDL-triglyceride clearance by brown adipose tissue in mice. Diabetes 63(3): 880-891.

28. Hao Z, Liu Y, Liao H, Zheng D, Xiao C, et al. (2016) Atorvastatin Plus Metformin Confer Additive Benefits on Subjects with Dyslipidemia and Overweight/Obese via Reducing ROCK2 Concentration. 124(4): 246250.

29. Holman R, Paul S, Bethel M, Matthews D, Neil H (2008) 10-year followup of intensive glucose control in type 2 diabetes. N Engl J Med 359: 1577-1589.

30. Hotamisligil GS, E Erbay (2008) Nutrient sensing and inflammation in metabolic diseases. Nature Reviews Immunology 8(12): 923-948.

ISSN: 2574-1241

DOI: 10.26717/BJSTR.2019.17.003073

Abdel-Azim Assi. Biomed J Sci \& Tech Res

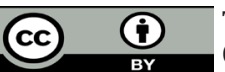

This work is licensed under Creative

Commons Attribution 4.0 License

Submission Link: https://biomedres.us/submit-manuscript.php
31. Latha S, Sheetal Chaudhary, Ray RS (2017) Hydroalcoholic extract of Stevia rebaudiana bert. leaves and stevioside ameliorates lipopolysaccharide induced acute liver injury in rats. Biomedicine \& Pharmacotherapy 95: 1040-1050.

32. Melis MS (1995) Chronic administration of aqueous extract of Stevia rebaudiana in rats: Renal effects. Journal of Ethnopharmacology 47(3): 129-134.

33. Moller DE (2000) Potential role of TNF-? in the pathogenesis of insulin resistance and type 2 diabetes. Trends in Endocrinology and Metabolism 11(6): 212-217.

34. Moodley K, Joseph K, Naidoo Y, Islam S, Mackraj I (2015) Antioxidant, antidiabetic and hypolipidemic effects of Tulbaghia violacea Harv. (wild garlic) rhizome methanolic extract in a diabetic rat model." BMC Complementary and Alternative Medicine 15(1): 408.

35. Ozbayer C, Kurt H, Kalender S, Ozden H, Gunes HV, et al. (2011) Effects of Stevia rebaudiana (Bertoni) extract and N-nitro-L-arginine on renal function and ultrastructure of kidney cells in experimental type 2 Diabetes. J Med Food 14(10): 1215-1222

36. Pari L, Latha M (2002) Effect of Cassia auriculata flowers on blood sugar levels, serum and tissue lipids in streptozotocin diabetic rats. Singapore Medical Journal 43(12): 617-621.

37. Sharma N, Mogra R (2009) Effect of Stevia extract intervention on lipid profile. Ethno Med 3(2): 137-140.

38. Singh S, Garg V, Yadav D (2013) Antihyperglycemic and antioxidative ability of S. rebaudiana (Bertoni) leaves in diabetes induced mice. Int J Pharm Pharm Sci 5(2): 297-302.

39. Singh S, Garg V (2014) Antidiabetic, antidyslipidymic and antioxidative potential of methanolic root extract of Stevia rebaudiana (Bertoni) on alloxan induced diabetic. J Pharm Pharm Sci 3(7): 1859-1872.

40. Stratton IM, Adler AI, Neil HA, Matthews DR, Manley SE, et al. (2000) Association of glycaemia with macrovascular and microvascular complications of type II diabetes (UKPDS 35): Prospective observational study. BMJ 321(7258): 405-412.

41.(1998) Effect of intensive blood-glucose control with metformin on complications in overweight patients with type 2 diabetes (UKPDS 34). UK Prospective Diabetes Study (UKPDS) Group. Lancet 352(9131): 854865 .

42. Uswa Ahmad, Rabia Shabir Ahmad, Muhammad Sajid Arshad, Zarina Mushtaq, Syed Makhdoom Hussain, et al. (2018) Antihyperlipidemic efficacy of aqueous extract of Stevia rebaudiana Bertoni in albino rats. Lipids in Health and Disease 17(1): 175.

43. Wang Z, Xue L, Guo C, Han B, Pan C, et al. (2012) Stevioside ameliorates high-fat diet-induced insulin resistance and adipose tissue inflammation by downregulating the NF-?B pathway. Biochemical and Biophysical Research Communications 417(4): 1280-1285.

44. Wei W, Zhao H, Wang A, Sui M, Liang K, et al. (2012) A clinical study on the short-term effect of berberine in comparison to metformin on the metabolic characteristics of women with polycystic ovary syndrome. Eur J Endocrinol 166(1): 99-105.

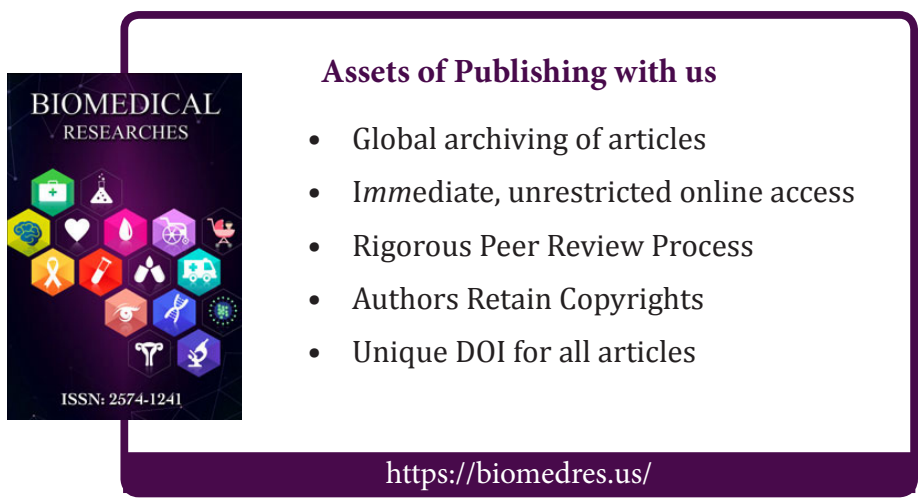

